\title{
Campo minado - sobre os princípios fundacionais da epistemologia da comunicação
}

Francisco Rüdiger

I- PUC-RS

Porto Alegre (RS), Brasil

Resumo: Surgiu entre teóricos do país e alhures a ideia de que, visando obter autonomia e cientificidade para a área, há propriedade em se falar e desenvolver a noção de "campo epistemológico da comunicação". Após relatar criticamente as teses de um de seus primeiros proponentes, defende o artigo que, não bastassem os problemas filosóficos internos, elas em pouco ou nada impactam no desenvolvimento do saber que pode surgir dos estudos de mídia, carecendo, portanto, de significado positivo para a ciência que neles pode haver.

Palavras-chave: epistemologia nos estudos de comunicação; Robert Craig; crítica.

Abstract: Mine field - On the foundational principles of the epistemology of communication The notion of "epistemological field of communication" has emerged among some theorists of our country and elsewhere as a tool that, if developed, could help the area obtain autonomy and, perhaps, scientificity. After critically reporting the theses of one of its major proponents, the article argues that, besides their internal philosophical problems, the theses have little or no impact on the development of knowledge that may arise from media studies, and therefore are meaningless for the science they may hold .

Keywords: epistemology in communication studies; Robert Craig; critique.

Surgiu já faz alguns anos, entre alguns acadêmicos brasileiros da área de comunicação, a pretensão de que, em vez da pesquisa empírica, histórica ou etnográfica, via de regra focada em tópicos de mídia, é pela prática da epistemologia que aquela primeira, a área, ganharia autonomia perante outros ramos do conhecimento científico. O "conhecimento comunicacional" até agora se confundiu com o proporcionado pelas pesquisas, métodos e teorias das ciências humanas - mas isso não equivale a uma condenação. A área teria como 
se emancipar dessa servidão, constituindo para si um campo de reflexão epistemológica autônoma, argumenta, por exemplo, nosso colega Jairo Ferreira.

Personagem de destaque nesse movimento em prol da epistemologia da comunicação, defende o autor em vários de seus textos que a área acadêmica da comunicação está fadada a ser apêndice ideológico da burocracia pública e do mercado, se não conquistar sua autonomia científica. Para ele, seus sujeitos precisam construir uma consciência epistemológica, um campo supostamente livre daquelas influências, para que estas últimas "possam ser superadas pelos atos de liberdade no conhecimento" (FERREIRA, 2007, p. 45; FERREIRA, 2008, p. 8).

A formação da área foi função da convergência dos interesses do estado e das empresas, que ali todavia seguem exercendo influência. A abordagem sociológica do assunto é, por isso, necessária a seu entendimento - mas cumpre notar que ela não tem como lhe fornecer legitimidade científica. As lutas pelo capital simbólico e apropriação de vantagens travadas em seu interior ensejam uma produção intelectual cujo exame também precisa levar em conta sua especificidade como saber, conforme inclusive ensinou Bourdieu.

De acordo com Ferreira, o aparecimento do campo da epistemologia da comunicação seria uma resposta ao problema, à necessidade que haveria de estudar as estruturas lógicas e interpretativas da produção científica e, portanto, dos conceitos e métodos usados "nos marcos institucionais do campo [acadêmico]" (FERREIRA, 2004, p. 117-118; FERREIRA, 2012, p. 33). O fato seria sinal da vontade da área em se emancipar cientificamente, visto que "a autonomização do campo acadêmico se expressa na autoconstrução de um lugar epistemológico discernido relativamente sobre outras formas de conhecimento" (FERREIRA, 2007, p. 49).

Tomando como referência os trabalhos de Robert Craig, referência originadora desta linha de raciocínio, vamos, no que segue, examinar com algum detalhe os argumentos que têm procurado embasar a tese, concluindo com a defesa da ideia de que, não bastasse estar deslocada filosoficamente, essa abordagem em pouco ou nada impacta no desenvolvimento do saber que pode surgir dos estudos de mídia - inegavelmente o núcleo duro da maior parte do trabalho realizado na área acadêmica de comunicação.

\section{Bastidores}

Análises que empreendemos em outras ocasiões discutiram a maneira como a causa da epistemologia da comunicação tem sido assumida por coletivo que, lançando mão dos recursos que a atividade acadêmica disponibiliza, almeja criar uma tendência de estudos cujo objeto, em vez dos fenômenos de mídia, é a estrutura e funcionamento da área que abstratamente deles trataria, e o projeto ainda não está claro se consiste, no essencial, em discutir suas próprias circunstâncias, trabalhar com vistas ao desenvolvimento 
da autonomia científica do campo de estudos da mídia, ou ainda as duas possibilidades juntas (RÜDIGER, 2014, 2016, 2017).

Em relação a tanto, Muniz Sodré todavia já alertou que

\begin{abstract}
A elaboração de uma epistemologia, bem o sabem os teóricos da produção do conhecimento, não precede o desenvolvimento dos saberes, antes acompanha a sua aquisição. [...] As regras do método aparecem progressivamente, na medida da produção do saber, na confusão dos erros e das verdades, das perdas e das descobertas [oriundas da prática de pesquisa] (SODRÉ, 1991, p. 11; WEBER, 1992, p. 157).
\end{abstract}

Para nós, significa afirmar que a reflexão epistemológica, seja ela praticada por quem for, só adquire propriedade se mantiver em vista as pesquisas empíricas, históricas e etnográficas de fato feitas na área de sua preocupação e, com base nelas, intervier nas discussões ensejadas pelo saber resultante destas pesquisas, por mais que elas sejam mediadas por outras questões. O resto pode ter seu encanto e, conforme a seriedade e rigor da proposta, merecer atenção - mas escapa ao campo da epistemologia, remetendo à filosofia política, à crítica cultural, ao debate de ideias, ao relato fenomenológico etc.

Consideremos as reflexões do norte-americano Robert Craig, nome de referência na proposição desta linha de raciocínio (cf., no entanto, ANDERSON, 1996). Segundo ele, o fato de a área acadêmica de comunicação carecer de paradigma, haver mais de uma teoria a respeito do que é comunicação, significa que, nessa área, ainda não há objeto de conhecimento científico. Assim sendo, prega, conviria, primeiro, examinar e discutir as teorias nela presentes, para, após chegar a eventual conclusão, decidir, em sendo possível, o que é comunicação com base em um ponto de vista melhor sustentado pelo viés epistemológico (CRAIG, 1999).

Para ele e outros (TABARES, 2010; VIDALES, 2013), a reflexão teórica sobre o fenômeno mundano da comunicação deve idealmente "produzir uma explicação unificada dos fenômenos de comunicação, por mais heterogêneos e múltiplos que sejam - respondendo, nomeadamente, a questões como a de saber o que é a 'comunicação', quais os 'elementos' e 'processos' que ela envolve, quais as suas 'formas' e 'níveis', quais as suas 'finalidades', e todos os demais aspectos do processo comunicacional" (SERRA, 2007, p. 52).

Como isso, no entanto, não tem sido obtido, o certo seria parar de teorizar sobre a comunicação, isto é: o processo mesmo, para, em vez dele, tratar das teorias a respeito. Na prática, a proposta significa que a teoria da comunicação não deve mais ser vista como um discurso reflexivo sobre a comunicação (social, por exemplo). Muito menos como um referencial analítico que ajudaria a pesquisar o assunto (isto é: os fenômenos de comunicação) do ponto de vista científico (empírico ou histórico).

Para Craig (1999) e seguidores, teoria da comunicação deve ser, antes de tudo, um metadiscurso: o discurso com que se fala sobre as teorias existentes sobre a comunicação humana no mundo acadêmico. De acordo com o primeiro, a comunicação se caracterizaria 
genericamente como uma "prática social", seja no cotidiano, seja na academia. Situando-se neste último campo, ela, entrementes, se articula em teorias. Estas importam porque "influem no discurso normativo que constitui e regula a prática da comunicação em nossa cultura". Os epistemólogos têm, portanto, um papel a exercer: "como acadêmicos e praticantes", escreve o autor, "nos encontramos engajados na comunicação [acadêmica] sobre a comunicação [social] na condição de participantes ativos" (CRAIG, 2006, p. 44-45).

Significa que a comunicação paradoxalmente adquire consistência disciplinar como campo acadêmico, na medida em que, embora sejam muitas as teorias, podemos reunilas em seis grupos para fins de estudo sistemático e racional (CRAIG, 1999). Ao teórico da área acadêmica portadora do título, comunicação não deve importar como objeto de teoria, visto que, diante do número e variedade de opções a respeito, só se pode ser, em tese, coerente focando em sua discussão metadiscursiva ("epistemológica").

A comunicação é, em si mesma, prática e discurso, não importa onde e como, de modo que, quanto mais se tenta defini-la, mais o saber se enrola e se perde em suas circunstâncias. A relação entre teoria e prática da comunicação se esfuma, na medida em que tudo, a teoria incluída, passa a ser prática de comunicação. O mundo não é senão um conjunto diferenciado de práticas. O foco da teoria deve, portanto, passar a ser apenas as teorias.

Craig não percebe que, ao definir a comunicação como uma prática social e uma forma de discurso, está propondo sua própria teoria a respeito (do fenômeno da comunicação). Para ele, o abandono do assunto aos praticantes do discurso normativo (seja na academia, seja no cotidiano) e a relegação do tratamento teórico da mídia aos outros não importam em prejuízo. Seriam ambas compensáveis com a contribuição que o campo de estudo das teorias da comunicação (em vez da comunicação mesma ou da reflexão sobre seus fenômenos mundanos) poderia dar ao esclarecimento da vida intelectual, à circulação de novas ideias e ao enriquecimento da comunicação na sociedade. A teorização das teorias, entre nós entendida com o termo epistemologia, não seria senão um desdobramento desta última circunstância.

A procura de uma teoria geral da comunicação pode, talvez, Ihe servir de pretexto para justificar o empreendimento, mas, de fato, está o autor convencido de que esta tarefa, elaborar uma teoria geral, se tornou missão impossível. O argumento, por ele lançado, de que, em compensação, com o estudo do campo teórico em vez da coisa mesma, talvez pudesse se abrir uma via própria para a comunicação adquirir sua distinção disciplinar em relação às demais ciências, todavia, também não cola — cabe-nos a observação.

Afinal, as teorias abordadas em nossa área, em sendo de origem alienígena, só estão nela, na área, porque a elas se prendeu um rótulo intitulado "comunicação". Fossem coerentes e não lhes faltasse coragem, os porta-vozes da epistemologia da comunicação deveriam tentar transferência para os departamentos de filosofia de suas universidades, visto que o metadiscurso com que discutem o campo não tem como provir de outra especialidade. 
De todo modo, fica a mensagem, para aquele que deseja saber o que é comunicação: evite buscar a resposta na experiência, mas também não a espere mais das teorias, porque se a primeira opção só gerará mais teorias, as teorias, sendo cada vez mais numerosas, se limitam a formar um campo intelectual, todavia autônomo, onde o que está em jogo são suas articulações conceituais, em vez da comunicação social/humana mesma.

As teorias não têm mais relevância ontológica ou, mesmo, prática, fora e dentro da pesquisa científica, devendo ser tratadas de modo essencialmente metodológico em um terreno abstrato, rigidamente blindado a toda e qualquer experiência histórica que não a oriunda do exame analítico ou reflexão abstrata.

\section{Análise}

Ampliando o comentário, percebe-se que, nesta linha de raciocínio, a teoria não tem nada a ver com pesquisa empírica, histórica e etnográfica: ela passa a formar um campo de discurso à parte e autônomo. Seu objeto são as próprias teorias da comunicação, incluindo as dos meios de comunicação (mídia). À revelia do emprego que elas possam ter em estudos de caso sobre a imprensa ou redes sociais, por exemplo, o foco está nas teorias - em abstrato. A teoria renuncia à mediação da prática de pesquisa, mas também da vida social, em favor de o que os brasileiros, conferindo ao termo um significado exótico, chamarão de epistemologia.

Shepherd e colaboradores tiram exemplarmente todas as consequências disso nos trabalhos reunidos em Communication as... (SHEPHERD, ST. JOHN, STRIPHAS, 2006), revelando que, no contexto, o objetivo da teoria não é mais ajudar a pensar a mídia ou mediar a sua investigação, muito menos intervir na prática social mais ampla, mas conectar rizomaticamente a palavra "comunicação" com tantas outras quanto possível no limite de páginas previsto para o volume, visto que a realidade só existe comunicada.

Para eles, fica claro, a comunicação só importa como objeto discursivo de uma espécie de teoria pura que projeta o termo por toda a existência. O assunto importa como tema de uma ensaística metafísica pós-moderna (SHEPHERD, 1993), em que se mistura a teoria estética e o texto literário informado filosoficamente, bem ao estilo da teoria crítica, mas tal como se passou a entender a expressão nos Estados Unidos (EAGLETON, 2005).

Nesse contexto, a comunicação, à primeira vista, se torna uma espécie de significante oco, capaz de acolher o significado que se desejar e, com persuasão, lograr impor-se durante os trabalhos. Como tudo é comunicação e o que, no caso, importa é a teoria a respeito, vale tudo, a começar por chamar teorias que não tratam da comunicação, antes a criticam, como tais ${ }^{1}$. A teoria passa a ser estudada por si mesma, constituindo um campo que, em sendo correto, todavia deveria ser lançado na conta da filosofia ou da teoria das ciências humanas, e não na da comunicação (VENERONI, 1989).

1 Exemplo claro disso seria a teoria crítica da indústria cultural, mas o argumento não exclui a chamada teoria da midiatização, cujas proposições podem, muito bem, se sustentar sem fazer referência à esfera da comunicação (em que pese o que diz, por exemplo, Muniz Sodré - cf. RÜDIGER, 2016). 
De acordo com nosso modo de ver, esta identificação do que seria uma reflexão metateórica, de ordem e interesse puramente filosófico, com a teoria da comunicação, responsável, entre alguns de nossos colegas, pela abertura da área de "epistemologia da comunicação", é, em seus próprios termos, um enorme equívoco. A proposição tira das teorias, tratem ou não especificamente do termo comunicação, os aspectos epistêmico e ontológico que poderiam torná-las significativas não apenas como tema de discussão filosófica, mas recurso de que eventualmente se poderia lançar mão na prática de pesquisa ou mesmo na pragmática cotidiana.

Na prática acadêmica, a formação do campo epistemológico da comunicação que assim se ensaia e, entre nós, vai se concretizando representa uma despedida da reflexão epistemicamente mais produtiva, na medida em que retira da teoria sua condição de princípio explicativo ou interpretativo de fenômenos empíricos, para convertê-la em tema de conversa e discussão sem poder ou influência na pesquisa, centrada que está no entendimento do significado puramente intelectual e filosófico das teorias, muito mais do que na avaliação de seu efeito epistêmico na investigação.

Craig (2013) mal esconde sua nostalgia neopositivista pela pesquisa social empírica focada no estudo da mensagem como via de unificação teórica e metodológica, isto é, de fundamentação científica da área acadêmica da comunicação humana, dominado que está pela fantasia de uma comunidade acadêmica disciplinada pela teoria (em vez de se articular pela prática e discussão da pesquisa).

O principal problema com sua proposta consiste, no entanto, em seu reducionismo epistemológico, em fazer a teoria sucumbir em discurso essencialmente abstrato, que nada acrescenta, nem no sentido de nos encaminhar à pesquisa dos fenômenos historicamente associados ao termo comunicação.

Nesse sentido, surpreende que, em vez de sinal do avanço de uma atitude niilista em relação ao tópico e à própria pesquisa científica feita na área acadêmica em foco, seu texto tenha, com o tempo, se tornado referência fundadora do "campo de estudos sobre teoria da comunicação [em abstrato]" (CRAIG, 1999). Considerando seus próprios termos com seriedade, pode isso levar a algum lugar do qual a cientificidade desses estudos, tais como de fato se manifestam, se beneficie? Pensamos que não é o caso. A proposta pode ser vista como sinal de época, indício da colonização da vivência pela figura da comunicação.

Do ponto de vista lógico e reflexivo, a epistemologia da comunicação, nome adotado para referir tal campo entre nós, é expressão que, se não comete, só tende a criar confusão em uma área que não precisa de mais². Atividade essencialmente filosófica, a epistemologia é resultado de uma vontade de esclarecimento e, assim, só pode se embaraçar onde vier a contribuir com desorientação.

2 Veja-se, por exemplo, o estudo de Tudor (2013), no qual se agasalha com o termo exame sem crítica da poética subjacente às teorias da comunicação. 
A epistemologia pode se ocupar da pesquisa e estudo dos fenômenos de mídia, na medida em que interessa a análise das bases teóricas e metodológicas desses estudos e pesquisas, o exame de suas articulações conceituais e argumentativas, a avaliação de seus feitos em relação ao saber existente. A tarefa não quer, porém, dizer que, com base em tanto, se possa estabelecer o que é o "comunicacional" e, assim, instaurar teoricamente uma nova disciplina, que seria a "Comunicação".

Fazê-lo sem mais significa, na verdade, pôr a "Teoria" no lugar da ciência, como durante algum tempo se pretendeu na França, nos dias de auge do estruturalismo (DOSSE, 1993/1994), e, agora, repetem alguns círculos acadêmicos norte-americanos e brasileiros em relação à figura da comunicação. Os estudos de mídia, sempre que envolvem pesquisa, isto é, criação de conhecimento procedente da experiência empírica, experimentação laboratorial e/ou exame documental, podem ter sua cientificidade, mas esta, salvo prova em contrário, nada tem de específico ou distinto da que há nas demais ciências humanas.

Que seja buscada a prova em contrário se admite sem reserva, embora a utilidade disso para o avanço da área seja duvidosa à luz dos exemplos disponíveis; isto é, considerando-se o estoque dos estudos de mídia - centro da maior parte dos trabalhos feitos na área acadêmica de comunicação em nosso país (MARTINO, 2014). Reservar para o campo acadêmico da comunicação a discussão e análise das teorias da comunicação como forma de lhe dar um objeto próprio e, assim, sua autonomia afigura-se, nessa perspectiva, projeto de virtual irrelevância.

\section{Criticismo}

Para nós, vamos deixar claro, a preocupação e o interesse em examinar e discutir epistemologicamente os estudos de mídia são legítimos, mas só na medida em que têm por eixo ordenador a pesquisa científica de fato feita sobre as experiências passíveis de agrupamento sob o rótulo ${ }^{3}$.

Que estes estudos tenham acabado por se abrigar em uma área acadêmica própria (chamada de "comunicação") é uma circunstância ligada à abrangência dos processos em que estão implicados seus meios (imprensa, televisão, internet etc.). O surgimento da área, recorde-se, foi um fato social, oriundo da divisão do trabalho intelectual, da conquista de novos territórios na academia, das disputas entre gerações profissionais etc.

Falando de modo geral, a pesquisa de mídia se desenvolveu no ponto de intersecção da crítica cultural, sociologia, linguística, economia, psicologia, filosofia política etc., visto que é delas que aquela extrai seus principais problemas, teorias e métodos de estudo: os meios e processos de comunicação são meros delimitadores materiais. As teorias efetivamente lastreadas no termo comunicação que por vezes - poucas - ela emprega

3 Reduzidas a conceitos relativamente puros, pesquisas científicas são, nas humanidades, empíricas, históricas e etnográficas. Logo, pesquisas teóricas têm outro estatuto lógico, delineando-se analiticamente, isto é, no plano típico-ideal, como trabalhos de cunho filosófico. 
provêm daquelas áreas, sempre que se vai além dos esquemas formais e de uns pobres conceitos oriundos da engenharia de comunicações e da cibernética de almanaque.

Paula Sibilia (2008) e Fernanda Bruno (2013), estudiosas academicamente pertencentes à área, por exemplo, oferecem-nos em seus belos trabalhos sobre, respectivamente, o exibicionismo midiático e a vigilância através dos meios digitais ensaios sociológicos estruturados em chave de crítica cultural e filosofia política em que não falta pesquisa e, em virtude do gabarito, poderiam ser apresentados em outros departamentos acadêmicos.

Por outro lado, Silvia Viana (2013) e Isleide Fontenelle (2002) elaboraram análises sobre, respectivamente, os reality shows e as cadeias de fast-food que, embora originados na área de ciências sociais, seriam admitidos sem nenhuma ressalva em fóruns próprios da área acadêmica agrupada sob o termo comunicação.

Schramm definiu a perspectiva que, na prática e desde o início, rege a área, afirmando que

não estamos em tempo de separar ou restringir nossos interesses de pesquisa e nosso campo mas, em vez disso, de explorar o máximo possível os outros campos em que nossos problemas se encontram em estudo e de multiplicar ao máximo o número de intercâmbios e alianças com os acadêmicos que trabalham com eles (SCHRAMM, 1958, p. 6).

O entendimento da epistemologia como exame ou teorização da área acadêmica da comunicação por si mesma, em abstrato, sugerindo, como o faz, a procura de uma essência que se esconderia nos seus prédios, gabinetes e laboratórios, para não falar na consciência de seu pessoal, em vez de análise crítica de suas atividades de investigação, revela um ponto de vista que até pode ter sua razão descoberta pela sociologia do conhecimento mas, pela ótica propriamente epistemológica, expressa um provincianismo de pouca serventia que, passando por alto os devidos cuidados, mais embaralha do que traz esclarecimento aos que desejam pensar a matéria.

Vista como estudo positivo das ciências, isto é, em atitude objetivante, a epistemologia não tem que se ocupar com teorias mesmas, mas com o modo como elas, por ventura, intervêm na pesquisa. As teorias variam das construções abstratas e descarnadas até, no máximo, os resumos de conexões empíricas, cujo conteúdo concreto varia enormemente, mas, como no primeiro caso, não pode ser avaliado em termos observacionais. A abertura para as discussões de tópicos essencialmente teóricos, embora em si mesma válida, em geral tem pouca ou nenhuma relevância na pesquisa e nos estudos de mídia, sempre que se fixa na questão da "comunicação".

Consideremos, a título de ilustração das nuances presentes no assunto, os trabalhos de Ciro Marcondes Filho (Jornalismo fin-de-siècle, 1993), McManus (Market-driven journalism, 1994) e Leandro Marshall (O jornalismo na era da publicidade, 2003). Nenhum deles constitui pesquisa científica, no sentido de levantamento, análise e interpretação especializada de matéria original, mas, antes, relatos sociológicos sobre o jornalismo. 
Em essência, não há, propriamente, neles pesquisa, mas ilustração e questionamento a respeito do assunto; exceto pela forma e independente dos méritos, eles poderiam ser classificados como ensaios fenomenológicos. Contêm leituras e expõe reflexões, mas não são, no sentido forte, relatos gerados de novo conhecimento empírico ou histórico.

Nesses casos, encontramo-nos perante trabalhos teóricos, fenomenologias, no sentido de que, mais ou menos, eles revelam predomínio de interesse reflexivo, ao contrário de outros, passíveis de interpelação enfática como teorias, no sentido de exposições gerais e mais ou menos abstratas sobre um dado assunto e dos quais daria exemplo o clássico de Adelmo Genro Filho (1987), O segredo da pirâmide.

Conforme Anderson y Ross (1998) advertem, estudar teorias não é o mesmo que construí-las, e construí-las não é o mesmo que trabalhá-las na pesquisa empírica ou histórica. Na pesquisa empírica, histórica ou etnográfica, as teorias, em vez de se aplicarem, como se costuma falar, interagem com a experiência, sob pena de aquela primeira não se fazer presente. A pesquisa, no caso, exige o planejamento de observações, o levantamento de documentação, a coleta de provas, as formulações pontuais, a construção casuística etc.

As teorias, é certo, ajudam-na a orientar-se em relação a tudo isso, mas só raramente respondem às descobertas que esta pesquisa pode acarretar sem alterações em seus teoremas. O pesquisador tarimbado e criativo não se contenta em testar teorias, enjambrando construções metodológicas de cunho analítico mais específico para dar conta de seus problemas de pesquisas e projetar suas descobertas.

A teoria, seríamos os últimos a negá-lo, tem importante papel na pesquisa, na medida em que sugere questões, esquematiza a exposição, fornece explanações ou permite interpretar resultados; mas não é a sua razão de ser, nem um objetivo que ela, a pesquisa propriamente científica, deveria perseguir. O investigador que se limita a aplicá-la, entende-a de maneira mecânica, no máximo lhe dá exemplos, prevenindo seu emprego produtivo. A pesquisa, no sentido forte, isto é: empírica, histórica ou etnográfica, consiste em fazer dialogar criativamente a teoria e a matéria, a reflexão conceitual e o exame da experiência em estudo ${ }^{4}$.

A reflexão essencialmente teórica pode e, às vezes, deve intervir nos trabalhos de epistemologia, mas não é essencial aos seus esforços, eles mesmos recomendáveis, mas de fato só eventualmente presentes de modo produtivo na prática da investigação. O principal, neste gênero, será sempre o exame crítico da pesquisa e a intermediação dos debates que se gera a partir delas, até para manter sob controle as tendências que, dado o fato de lidar com a mídia, o campo revela no sentido político e ideológico.

Os estudos de mídia, em seu aspecto de pesquisa, se fundam em campos científicos que, colaborando em conjuntos ou intervindo isoladamente, só raramente se inserem epistemologicamente no âmbito conceitual e analítico representado pelo termo

4 Apesar de se apresentar como "exercício de natureza metodológica", Mortes em derrapagem (1991), de Fausto Neto, por exemplo, constitui modelo de relato de pesquisa em que, embasada numa problemática teórica, a análise documental conduz à reflexão específica sobre um fenômeno midiático em particular. 
"comunicação". Os trabalhos do gênero, via de regra, carecem de métodos próprios, operam com problemas ordenados por outras categorias e recorrem às teorias das ciências humanas para articular seus argumentos - só pertencem à área administrativa da comunicação porque foi sob este título que se institucionalizaram academicamente.

A comunicação pode, por óbvio, se tornar conceito ordenador ou motivo para invocar uma teoria adequada em uma ou outra investigação, mas não é uma categoria essencial à estruturação epistemológica da área de estudos de mídia, verá qualquer um que revise os principais trabalhos de investigação nela desenvolvidos. As teorias da comunicação em geral não o são de fato (MARTINO, 2017, p. 173-178) - apenas são chamadas assim, visto que outros termos de fato possuem relevância; e, sendo caso, costumam ter pouca relevância no desenvolvimento da investigação, dado o cunho muito abstrato e genérico da categoria.

As ciências que, no século passado, convergiram para desenvolver os estudos de mídia não se orientam única nem majoritariamente por ela. Os interessados se valem mais ou menos informalmente do termo comunicação para se orientarem em relação a outros campos de experiência e investigação. O fato, porém, é que não é certo nem necessário que conduzam seus trabalhos de pesquisa de acordo com as teorias que insistem no conceito: há muitas outras disponíveis, como fica claro à sua consciência epistemológica mais esclarecida.

A primeira orientação conceitual dada a quem se aproxima do campo acadêmico da comunicação passa, ainda hoje, pelo enquadramento mais clássico da expressão (remetente-mensagem-destinatário), mas, conforme nos afastamos do ponto de origem, seja individual, seja coletivamente, mais e mais se vê que a função desse esquema, hoje simplório, é essencialmente formal e que, se quisermos avançar, propondo algo significativo e inovador, é preciso explorar outras problemáticas teóricas, muitas vezes indiferentes à questão comunicacional, conforme a definem teorias que, em geral, provêm da filosofia e ciências sociais (RÜDIGER, 2010).

\section{Conclusão}

As teorias da comunicação remetem a algo que passou a fazer parte do mundo, a processos e acontecimentos aos quais se colou este termo, comunicação: elas são sua forma mais ou menos polêmica e elaborada de definição. A comunicação, é fato, se tornou base de uma ontologia, na medida em que, aos poucos, passou a importar em vários graus e sentidos para a ação e a reflexão humana.

O ponto, contudo, não deve nos fazer esquecer que, apesar disso, ela só excepcionalmente pode ser pesquisada em atitude científica positiva. A categoria tem pouca ou nenhuma relevância nos estudos empíricos e históricos mais significativos feitos na área que, epistemologicamente, melhor chamaríamos pelo termo "estudos de mídia".

Dependendo de sua formatação, "comunicação" é palavra que, na pesquisa, até pode funcionar bem para dar conta de alguns fenômenos imediatos, microssociológicos ou, 
na reflexão teórica, ensejar um raciocínio de alcance mais abstrato e universal. Mas, vendo bem, não é muito útil como recurso analítico e, mesmo, interpretativo nos estudos de mídia e suas manifestações. Neles, costuma ter uma função predominantemente retórica ou simplesmente anódina.

A prova está no patetismo que provocam nos verdadeiros pesquisadores do assunto aqueles que, por exemplo, se propõem a estudar empírica e analiticamente um periódico ou a programação de uma estação de rádio ou televisão com os conceitos da teoria da ação comunicativa, da ciência da mídia kittleriana ou da Escola de Palo Alto.

"Campo epistemológico da comunicação" é expressão que, considerada com rigor, só faz sentido referida aos estudos científicos sobre os temas de interesse da área acadêmica-administrativa designada pelo seu último termo ("comunicação"). Ajuizar a respeito do referido campo amparando-se apenas em abstrações pode ter relevância para uma reflexão genérica sobre esse termo, mas, via de regra, em pouco ou nada impacta no desenvolvimento da investigação científica assumida pela área, cada vez mais orientada pela noção de "mídia".

À filosofia cabe, sempre que se apresenta o caso, analisar e discutir as teorias, seja em abstrato, seja na prática de pesquisa: o contraponto entre teorias, sempre que envolvem um aspecto epistêmico na prática de investigação, é bom tópico de epistemologia. O confronto de ideias a que elas podem dar lugar, não; é algo que foge à missão desta última, por maior que seja o interesse e validade daquelas teorias.

A tarefa não pertence à mesma classe de discussão: cairia, sempre que de fato lidasse com o termo comunicação e o analisasse do ponto de vista conceitual, em uma ou outra área da filosofia e/ou da história do pensamento, defenderá uma reflexão epistemológica não provinciana.

Que a reflexão epistemológica possa ser útil ou adquira relevância depende muito de fatores que transcendem o plano lógico-formal, ao envolver formação intelectual, sabedoria prática, fineza espiritual, visão de contexto e outras tantas virtudes que se conhece quando se apresentam, mas escapam aos métodos e desenvolvimentos tecnológicos e científicos.

A pesquisa se aprende na prática, pela assimilação de bons exemplos. A crítica colabora para o seu desenvolvimento, na medida em que questiona suas provas e argumentos. A metodologia vem depois, para esclarecer e sistematizar abstratamente algo que foi proposto alhures. Os manuais de receita e as propostas megalomaníacas feitas em abstrato, de nenhuma exequibilidade, só servem de exemplo negativo.

Francisco Rüdiger é professor dos cursos de comunicação e filosofia da UFRGS e do Programa de Pós-graduação em Comunicação da PUC-RS. É doutor em ciências sociais pela USP e mestre em filosofia pela UFRGS.

frudiger33@gmail.com 


\section{Referências}

ANDERSON, J. Communication theory. Nova York: Guilford Press, 1996.

ANDERSON, R.; ROSS, V. Questions of Communication. 2a. ed. Nova York: St. Martins Press, 1998.

BOURDIEU, P. (Org.). El oficio de sociólogo. Mexico: Siglo XXI, [1973] 1975.

BRUNO, F. Máquinas de ver, modos de ser. Porto Alegre: Sulina, 2013.

CRAIG, R. Teorias da comunicação. Cotia: Ateliê, 2007. $\overline{119-161}$.

Communication theory as field. Communication theory, Nova York, n. 9, may 1999. P.

. Communication as practice. In: SHEPHERD, J. et al. (Org.): Communication as... Thousand Oaks: Sage, 2006.

Constructing theories in communication research. In: COBLEY, P.; SCHULZ, P. (Org.): Handbook of Communication Science I: theories and models of communication. Amsterdam: De Gruyter, 2013.

DOSSE, F. História do estruturalismo. São Paulo: Unesp, 1993/1994. 2v.

EAGLETON, T. Depois da teoria. Rio de Janeiro: Civilização Brasileira, 2005.

FAUSTO NETO, A. Mortes em derrapagem. Rio de Janeiro: Rio Fundo, 1991.

FERREIRA, J. Epistemologias das sociedades ideais. Logos, Rio de Janeiro, n. 19, v. 2, 2012. p. 29-42.

Elementos para uma crítica à cisão sujeito e objeto nas matrizes epistemológicas da comunicação. Lumina, Juiz de Fora, n. 2, v. 2, 2008. p. 1-11.

. Questões e linhagens na construção do campo epistemológico da comunicação. In: FERREIRA,

J. (Org.): Cenários, teorias e epistemologias da comunicação. Rio de Janeiro: E-papers, 2007.

Campo acadêmico e epistemologia da comunicação. In: LEMOS, A. et al. (Org.). Mídia.br. Porto Alegre: Sulina, 2004.

FONTENELLE, I. O nome da marca. São Paulo: Boitempo, 2002.

GENRO FILHO, A. O segredo da pirâmide. Porto Alegre: Tchê, 1987.

MARSHALL, L. O jornalismo na era da publicidade. São Paulo: Summus, 2003.

MARTINO, L. C. Escritos sobre epistemologia da comunicação. Porto Alegre: Sulina, 2017. p. 11-31.

Trilhas de um espaço de pesquisa. Mídia, cultura e consumo, São Paulo, n. 11, v. 31, 2014.

RÜDIGER, F. Epistemologia 'da' comunicação: elementos para a crítica de uma fantasia acadêmica. Revista Famecos n. 21, v. 2, 2014. p. 395-412.

Questionamentos a uma teoria crítica da comunicação que se apresenta como ciência: sobre a antropologia filosófica da comunicação de Muniz Sodré. In: FREITASs, Cristiane (Org.): Mídia e tecnologia. Porto Alegre: Sulina, 2016.

. Da epistemologia como projeto especulativo: a ciência da comunicação segundo José Luiz Braga. Revista Eptic v. 19, n. 3, 2017. p. 7-22.

SCHRAMM, W. The challenge to communication research. In: NAZFIGER, R.; WHITE, D. (Org.): Introduction to mass communication research. Baton Rouge: Louisiana State University Press, 1958. 
SERRA, J. Manual de teoria da comunicação. Covilhã: LabCom, 2007.

SHEPHERD, J. Building a discipline of communcation. Journal of Communication, Thousand Oaks, n. 43, v. 3, 1993. p. 83-99.

SHEPHERD, J. et al. (Orgs.). Communication as... Thousand Oaks: Sage, 2006.

SIBILIA, P. O show do eu. Rio de Janeiro: Relume, 2008.

SODRÉ, M. Apresentação. In: NEIVA, Eduardo. Comunicação: teoria e prática social. São Paulo: Brasiliense, 1991.

TABARES, J. Epistemologia de la comunicación. Medellin: Universidad de Medellin, 2010.

TUDOR, M. A. Epistemologie de la communication. Paris: L'Harmathan, 2013.

VENERONI, F. Elementos para una critica de la ciencia de la comunicación. Cidade do México: Trillas, 1989.

VIANA, S. Rituais de sofrimento. São Paulo: Boitempo, 2013.

VIDALES, C. El relativismo teórico en la investigación de la comunicación. In: EDWARDS, A. et al (Org.): La producción del conocimiento en las ciencias de la comunicación. Coahuila: AMIC, 2013.

WEBER, M. Metodologia das ciências sociais. v. 1. São Paulo: Cortez, 1992.

Artigo recebido em 9 de março de 2017

e aprovado em 22 de janeiro de 2018. 